\title{
Geoelectricity Data Analysis For Identification The Aquifer Configuration In Bandorasawetan, Cilimus, Kuningan, West Java Province
}

\author{
M. Kurniawan Alfadli $i^{1 *}$ and Nanda Natasia ${ }^{1}$ \\ ${ }^{1}$ Faculty of Geological Engineering, Padjadjaran University, Jalan Raya Bandung Sumedang Km. 21, Jatinangor, West Java
}

* Corresponding author : m.kurniawan@unpad.ac.id

Tel.: +62-856-6929-8592;

Received: Oct 19, 2017. Revised : Nov 15, 2017, Accepted: Nov 30, 2017, Published: 1 Dec 2017

DOI : 10.24273/jgeet.2017.2.4.779

\begin{abstract}
Indonesian water consumption is influenced by the people growth. One of Water consumption fulfilment by groundwater aquifer. Bandorasaw etan is one of the areas which predicted have proper potential due to located in East of Mt. Ceremai that predicted recharge area. Based on regional geological data, Bandorasawetan is an undifferentiated young volcanic product which consists of lava, breccia, lapilli, and tuffaceous sand. Geophysics method for groundwater prediction is 2-D geoelectrical with Wenner - Schlumberger configuration. The result of acquisition is obtained resistivity value from 0 - >1000 Ohm. m. Interpretation from data distribution is consist of two resistivity range that describes lithology on the research area, such as: 0 - 150 Ohm.m contributed as aquiqlud with tuffaceous sand lithology and $>150$ Ohm.m interpreted as volcanic breccia lithology. Volcanic breccia has a role as aquifer in study area, the conclusion is distribution of resistivity value with range $>150$ Ohm.m be the reference to developing groundwater resource in study area. Depth of aquifer is varying, deeper to the east. In Line - 1, depth of the aquifer is 48 meters and in Line - 2, depth of aquifer be 60 meters.
\end{abstract}

Keywords: Mt. Ceremai, Bandorasawetan, geoelectric, groundwater, aquifer.

\section{Introduction}

Naturally, availability of water depends on water capacity in the groundwater basin. In rainy season, surface water as one of the water supplier came from runoff and groundwater. But in dry season, the water supplier only came from groundwater system. Therefore, to fulfil water availability in dry season is affected by groundwater resource.

Groundwater form in monthly until thousand years, depends on rain and geological condition with complexity situation limited by hydrogeological boundary, hydrogeological event such as recharge, flowing, and discharge has an aquifer integration system that influences groundwater availability, with the result that groundwater is an importance and strategical resource.

In order to preserve the groundwater resource continuously in unbalance system between the supplier and necessity, groundwater system must be organizing depend on social environmental, economic functions in harmonious and synergy integration.
Bandorasawetan has indication of groundwater potential, therefore need some investigation to ensure the fact, so the potential uses for public welfare. Resistivity method or geoelectric used electrical property of materials in subsurface for obtaining anomaly and electrical subsurface distribution. This method effectively for shallow and intermediate mapping.

\section{Research Area}

As geomorphology aspect, research area is located at the volcanic hill with rather steep area, it concluded from topography map, it describes that elevation of research area is at 475 - 575 meters (Fig. 2). For the slope of Fig. 3, maximum slope in research area is 15 degrees. Majority is dominated by slope with tilt from 2 to 5 degrees. The classification is divided become three types, namely:
1. Decline area ( $0-2$ degrees)
2. Rather Steep Area ( 2 - 5 degrees)
3. Steepest area ( $>5$ degrees).

This varies from morphometry is described by undulation topography in research area. 


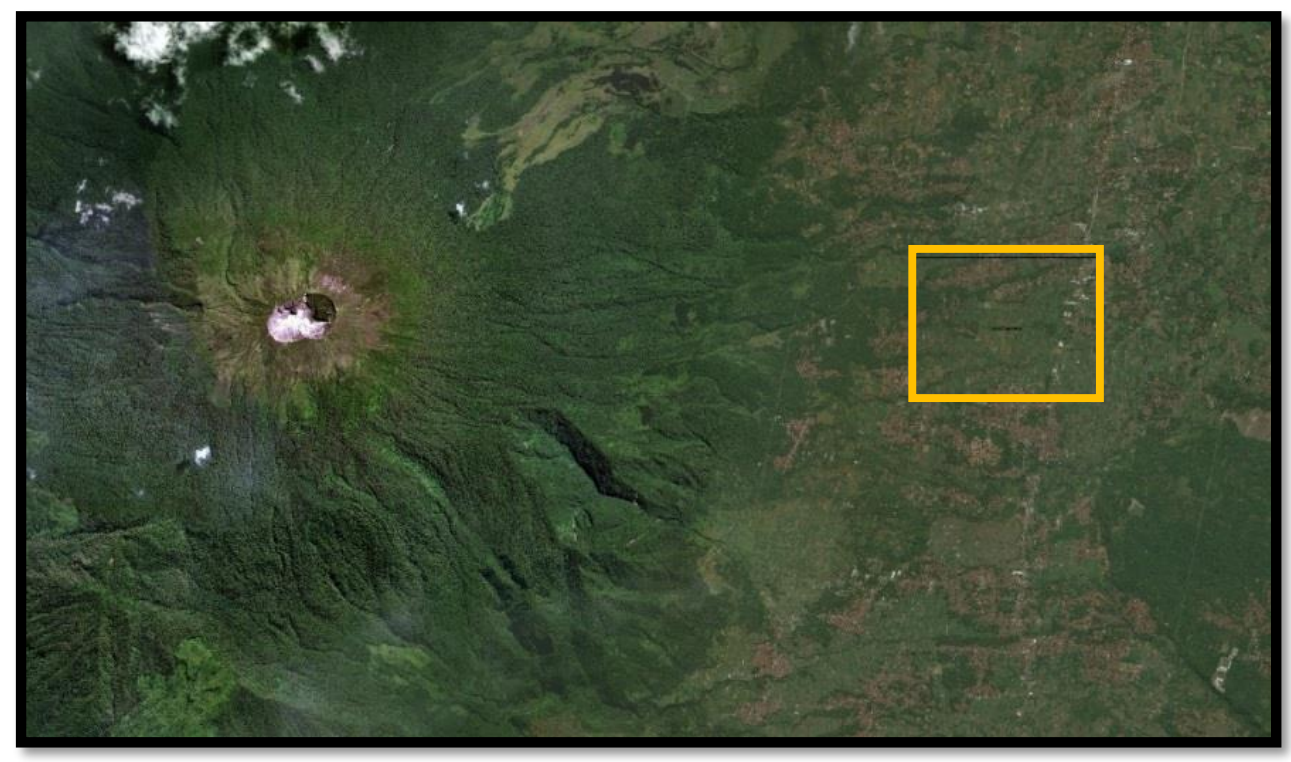

Fig. 1. Location of Resistivity Acquisition

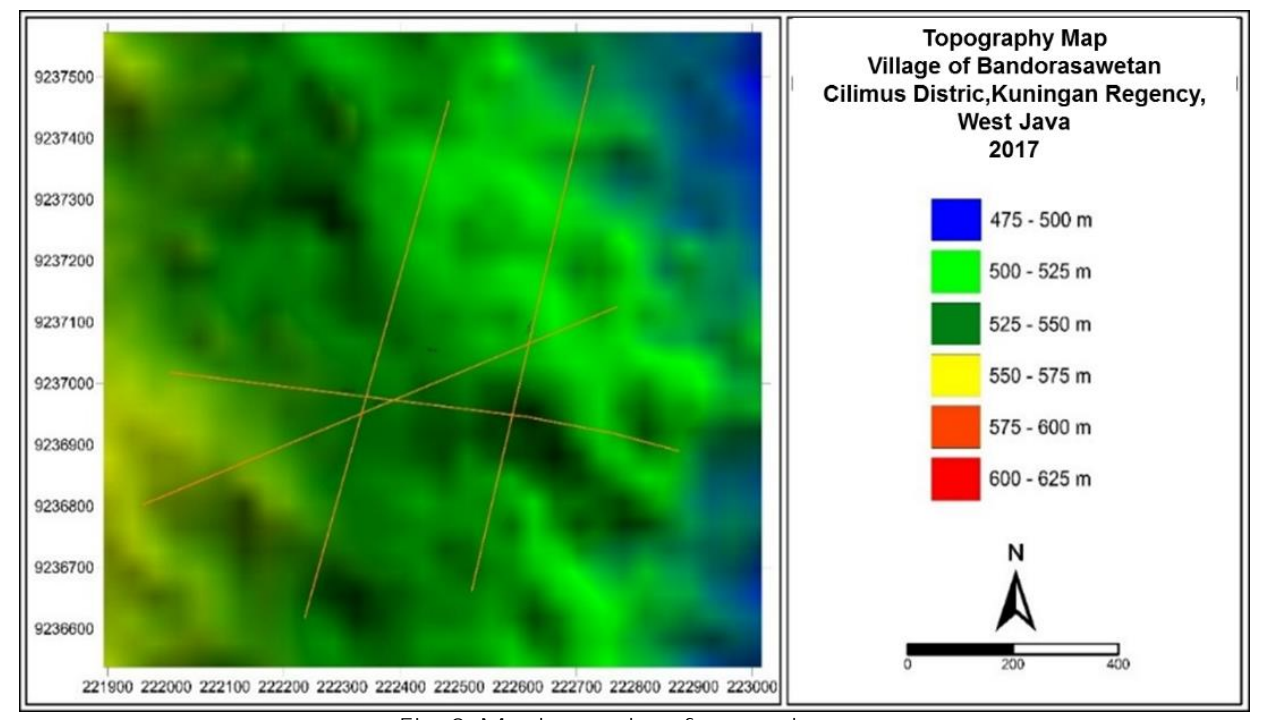

Fig. 2. Mophography of research area

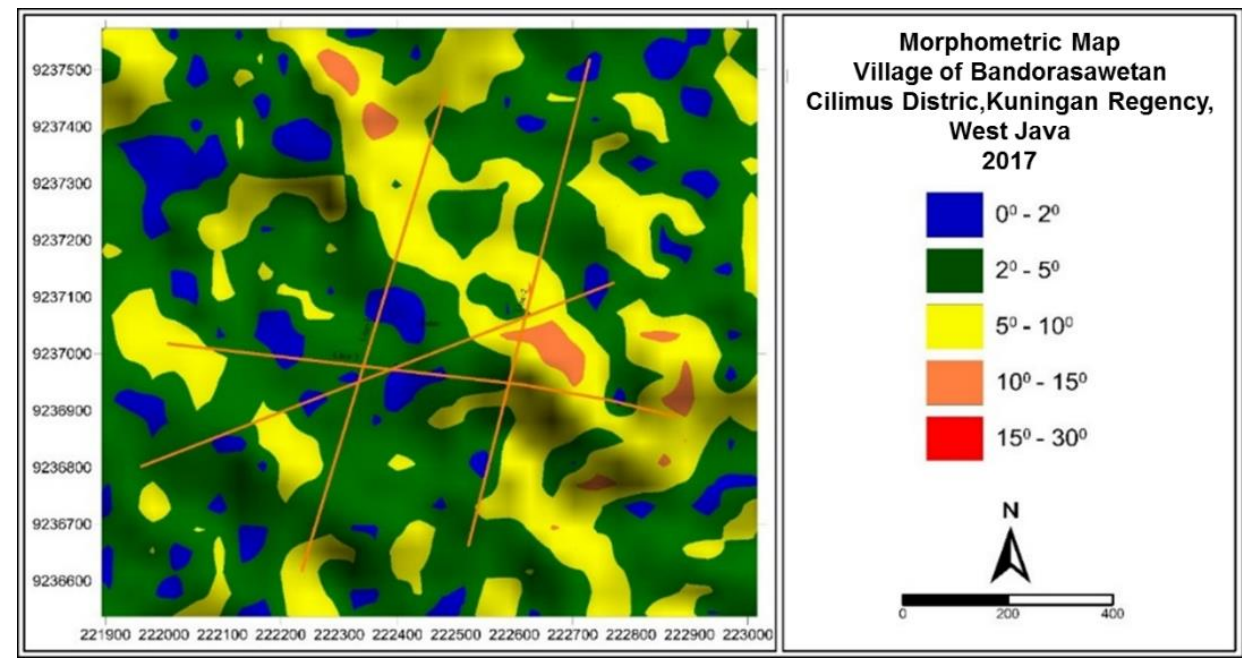

Fig. 3. Morphometry of research area. 


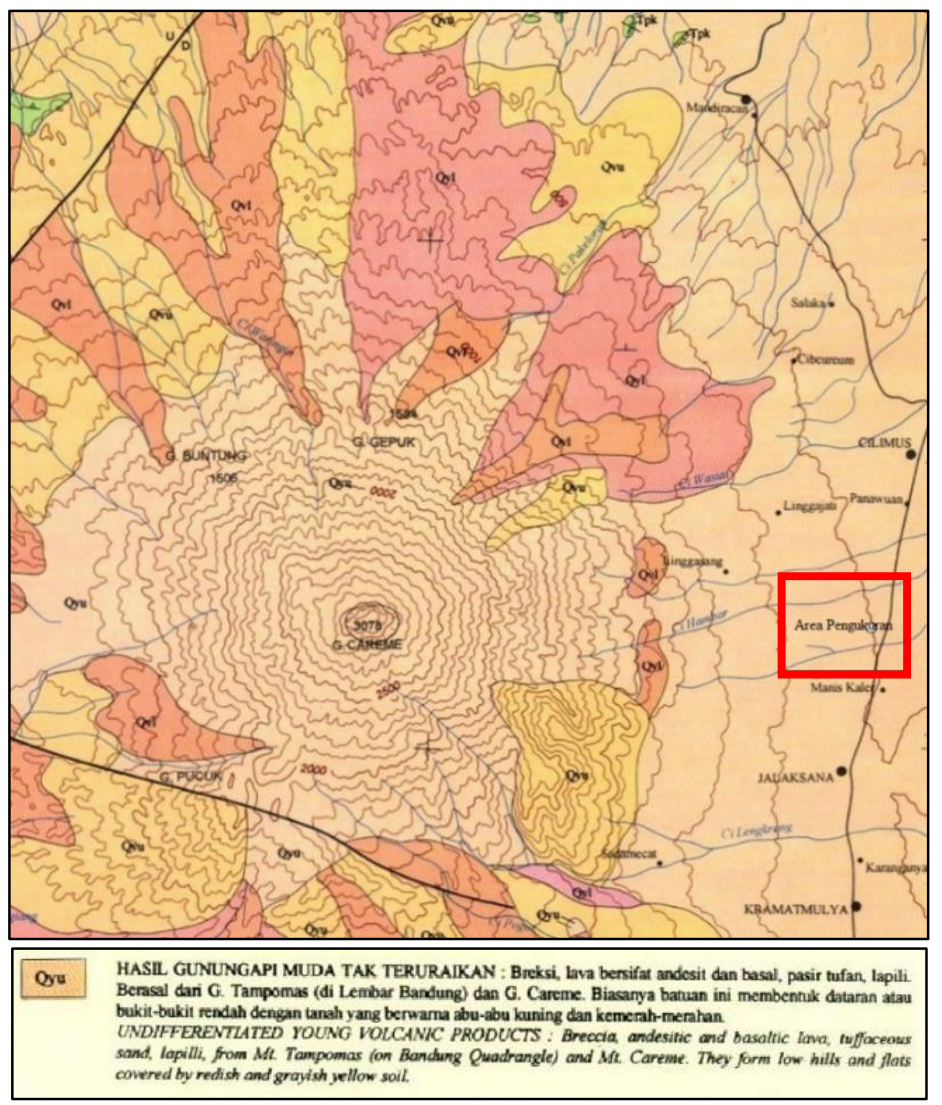

Fig. 4. Geology Regional Map of Research area (Red Box describe location of geoelectric research)

\section{Geology of Research Area}

Regionally, research area constitutes east Mt. Ceremai volcanic deposition. This area including in Indonesian Geology Regional Map in Cilimus Sheet (Fig. 4).

Overlapped map between geology and geoelectric location resulted that the research area located in Qyu formation i.e. Undifferentiated Young Volcanic Products with lithology namely: breccia, lava, tuffaceous sand, and lapilli. From geological information, needed identification to describe the aquifer system in research area. Resulted from geology are tuffaceous sand interpreted as an aquiclude, volcanic breccia has harder layer than tuffaceous sand with high resistivity value.

\section{Methodology}

Geophysical investigation that used in this study is indirect - non-destructive (surface) test electrical resistivity method using Schlumberger array (Reynold, J.M, 1998 ; Santoso,D, 2002).

In the Wenner-Schlumberger method, the depth of the identified layer is determined by the distance of the current electrode, as to obtain the resistivity in varying depths the measurements are made at varying $A B$ spacing by increasing the interval of the current electrode. When the measured potential difference is very small with respect to the very large current electrode distance, the potential electrode spacing may be enlarged.
Measurements are intended to measure the value of the electrical resistance of the rock, which in a particular type of device the value is read directly, but on other types of equipment reads the current and potential. Multiplication of electrical resistance value by geometry factor yields apparent resistivity value $(\mathrm{pa})$.

An electrical resistivity survey was made using 2-D method that aims to see the distribution of resistivity values vertically and laterally (Telford et al, 1990).

\subsection{Data Processing And Interpretation}

Apparent resistivity $(\rho \alpha)$ value that occurred in the field measurement gives the average resistivity value through multiple heterogenic layers that have a different resistivity value (loke, 2000; loke 2004).

Since the apparent resistivity was cames from multiple unique layers, the value can be written in:

$$
\rho_{\alpha}=\frac{2 \pi \Delta V}{I}\left[\frac{1}{\left(\frac{1}{r_{1}}-\frac{1}{r_{2}}-\frac{1}{r_{3}}-\frac{1}{r_{4}}\right)}\right]^{-1}
$$

while the geometrical factor $(\mathrm{K})$ can be written as:

$$
K=\frac{2 \pi}{\left(\frac{1}{r_{1}}-\frac{1}{r_{2}}-\frac{1}{r_{3}}-\frac{1}{r_{4}}\right)}
$$


where $(K)$ is constant, depends on the electrode arrangement used in measurement. By combining with the equation (1) and (2), ( $\rho \alpha)$ can be written as:

$$
\rho_{\alpha}=K \frac{\Delta V}{I}
$$

While there is no homogeneous medium in earth, the resistivity of the layer will be different. the apparent resistivity can be assumed as an apparent medium that equivalent with layered medium that measured. In an electrical resistivity survey performed in non-homogeneous medium (variable resistivity vertically and horizontally), the apparent resistivity will give a qualitative image of resistivity distribution below the surface. apparent resistivity at layered medium can be described in Fig. 6. if measured medium consists of two-layer ( $\rho 1$ and $\rho 2$ ) where $\rho 1>\rho 2$, any current flowing between electrode $A$ and $B$ will give a different image at each layer. in the measurement, those medium is assumed as one single homogeny layer that has single resistivity value $(\rho 1)$. Conductance of this apparent medium is equal to sum of each layer conductance. by using specific electrode configuration, value of $\mathrm{K}$ can be predicted. Potential and current that injected was known, than the apparent resistivity can be calculated.
By changing electrode spacing for exploration necessities, the resistance value in different depth can be known. Field acquisition value after the apparent resistivity was calculated, is a function of the electrode configuration and their depth of penetration. The longer distance between electrodes, deeper penetration is achieved that measured by current flowed in the electrode (Santoso, 2002).

The data processing result will produce 2-D geoelectric section with a certain direction with elevation information. These results show the actual distribution of resistivity values that will be correlated with geology and obtained interpretations that describe the subsurface conditions of the study area (Fettter,1988; Heiken, G. \& Wohletz, K, 1992).

\section{Result And Interpretation}

The resistivity section of the modelling results from line- 1 through line- 4 that have been corrected against topography (Fig.s 7 to 10) can be divided into several ranges of resistivity values/resistance types represented by layers of a certain colour. Each colour layer can be interpreted as a package of rocks.

The overlapped colour can be divided into two rock packs contained in the measurement area (Table 1).

With the division of the above package can be obtained interpretation results in Fig 7 - Fig. 10.

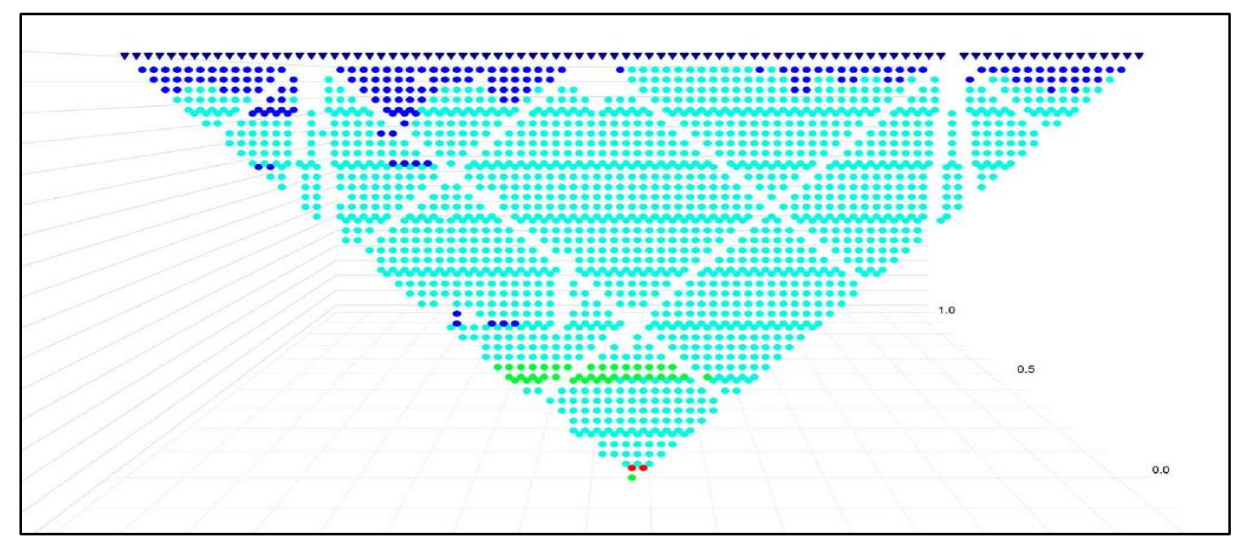

Fig. 5. 2D Electrical resistivity stacking chart

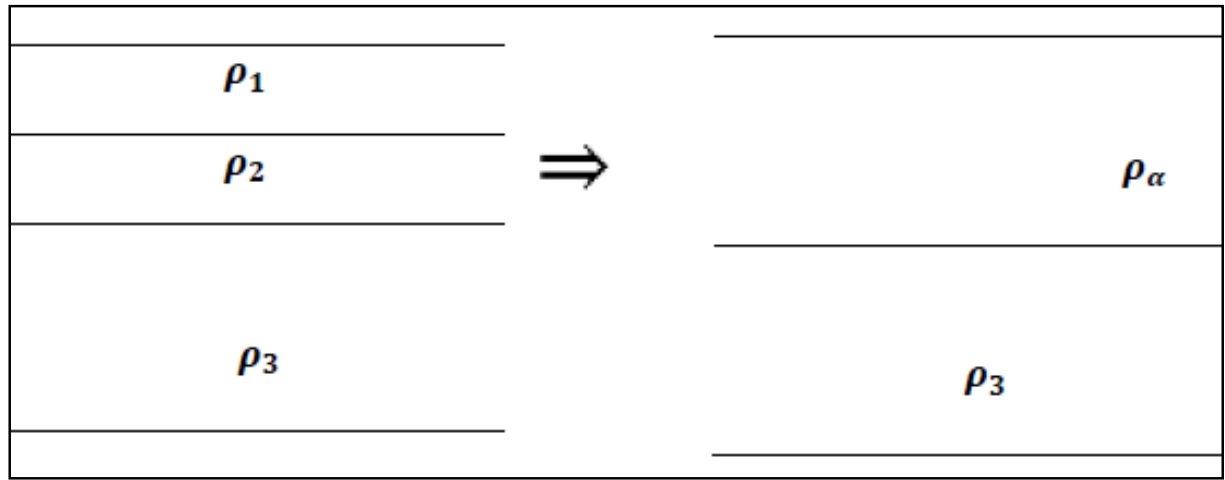

Fig. 6. apparent resistivity in layered medium 
Table 1.

Resistivity Ratio of correlation result with geology of research area

\begin{tabular}{|c|l|}
\hline Resistivity & Description \\
\hline $0-150$ Ohm.m & $\begin{array}{l}\text { Low resistivity values from the surface to a depth of } 170 \text { meters. The rock } \\
\text { packet with this resistivity value is estimated as aquiqlud in the form of tufan } \\
\text { sand rock. }\end{array}$ \\
\hline$>150$ Ohm.m & $\begin{array}{l}\text { This high resistivity value is a harder rock in the measurement area. Expected } \\
\text { as a breccia and has a varying depth distribution. }\end{array}$ \\
\hline
\end{tabular}

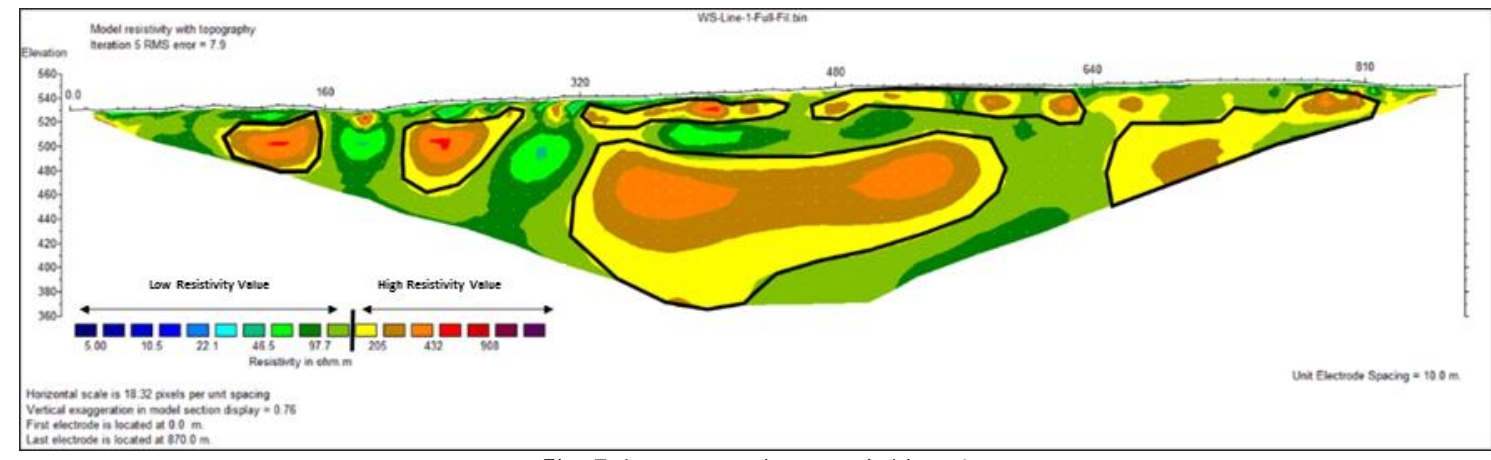

Fig. 7. Interpretation result Line-1

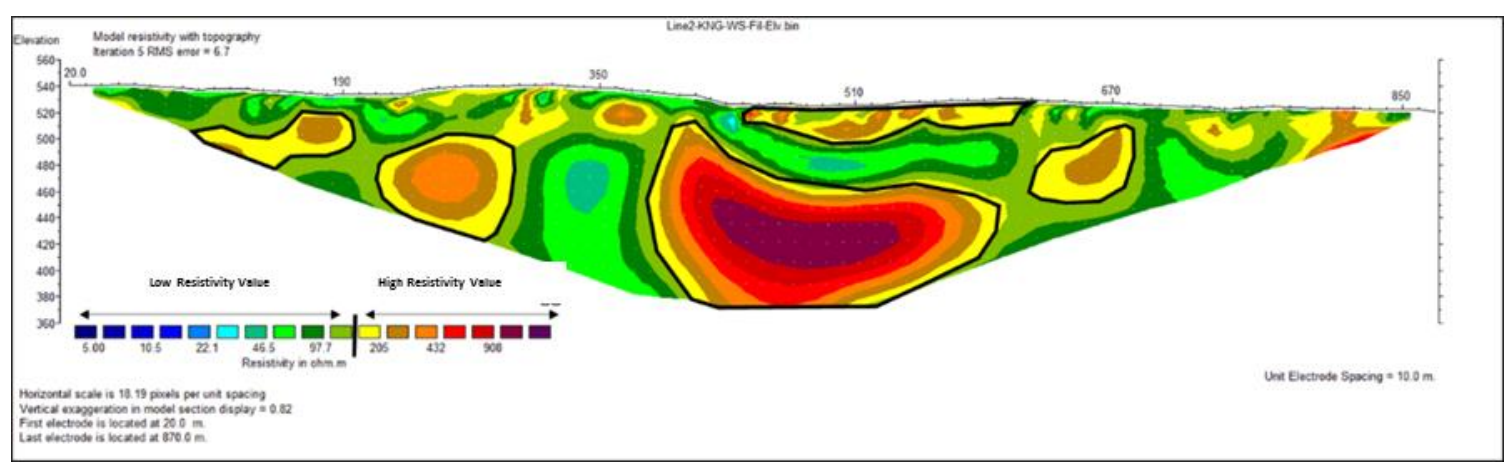

Fig. 8. Interpretation result Line-2

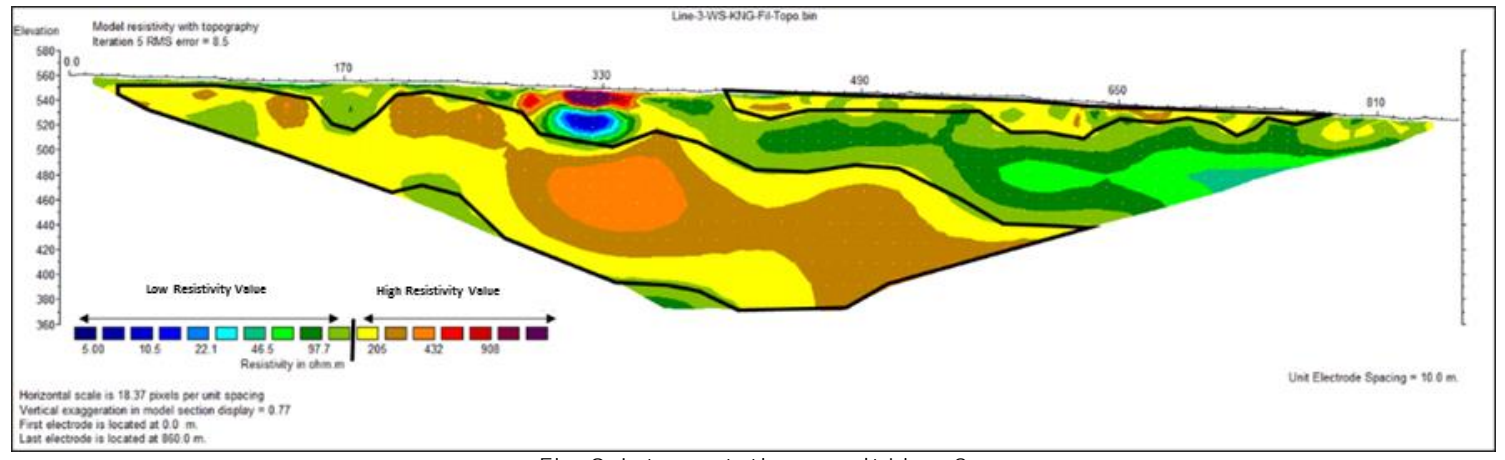

Fig. 9. Interpretation result Line-3

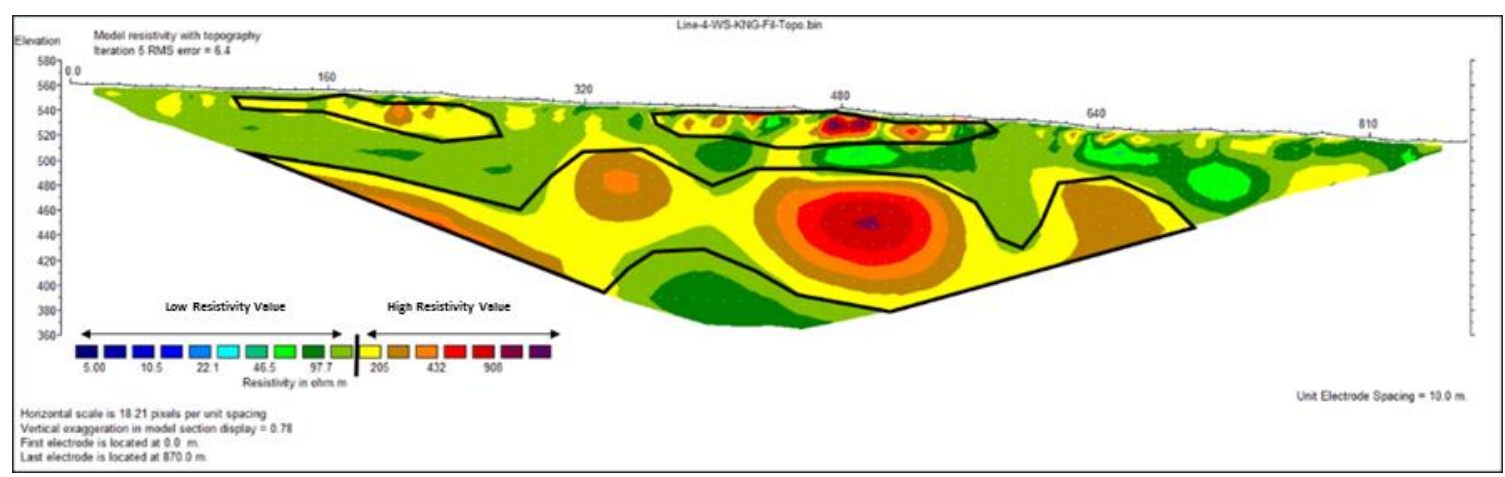

Fig. 10. Interpretation result Line-4 
Furthermore, the results of data processing and analysis of the distribution of resistivity value can be made in the form of a fence diagram to see the distribution of distribution of rock packets in the research location. Based on the fence diagram model (Fig.11)

The light blue line in the fence diagram above indicates the boundary of the exploration target area and below is the inversion model of 2-D geoelectric data. From this fence, diagram can be seen the direction of the measurement Line is two trajectories north-south direction, one trajectory west-east direction and one trajectory SouthwestNortheast with the distribution of resistivity ranging from 5 ohm.m to more than 908 ohm.m.

From Fig. 11 it can be seen that the westward direction of the line, distribution of resistivity is increasingly in a deep position according to the topography of the measurement area. While the dimension ins thickening seen by comparing Line 1 and Line 2 which shows the distribution of high resistivity value that diminishes its dimension to the Line 2. The depth position is shown by correlating the three Lines, especially on the 2nd track which is very clear showing the value position is increasingly low and is supported by Line 2 which shows a deeper position of high resistivity value. In Track 1 the position of high resistivity value having a large dimension ranging from 48 meters depth while on the 2 nd track the high resistivity position correlated with the track 1 starts at a depth ranging from 60 meters.

In addition to the fence diagram analysis, 3D models are also created that illustrate the subsurface conditions of the distribution of resistivity values. The resistivity value is then cut with a 150 Ohm.m Limit above and suspected as a water-retaining layer (Fig. 12 and Fig. 13).

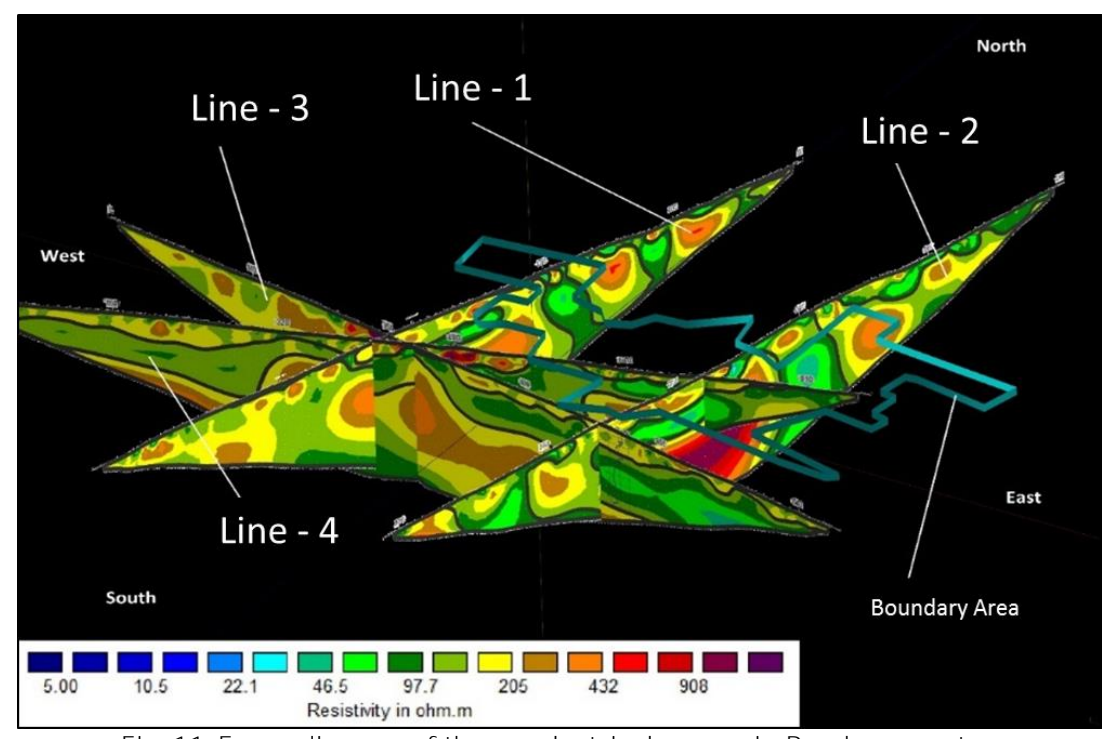

Fig. 11. Fence diagram of the geoelectrical survey in Bandorasawetan

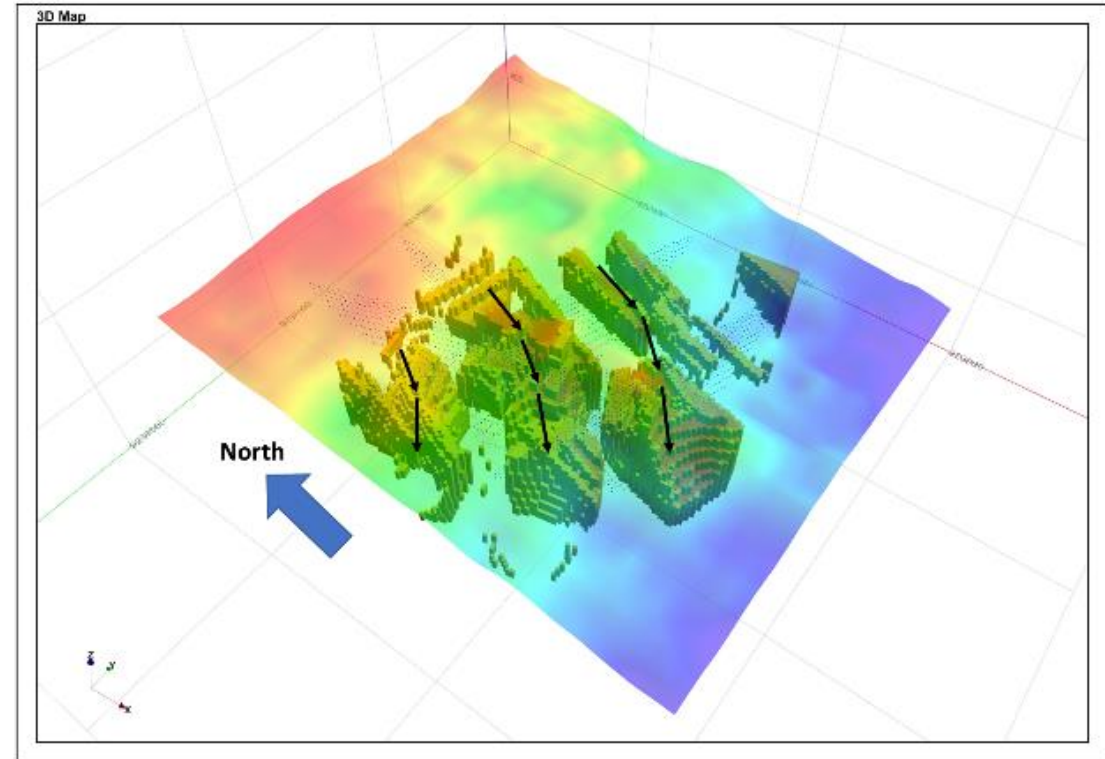

Fig. 12. top view of 3D model of resistivity interpreted as aquiver, 


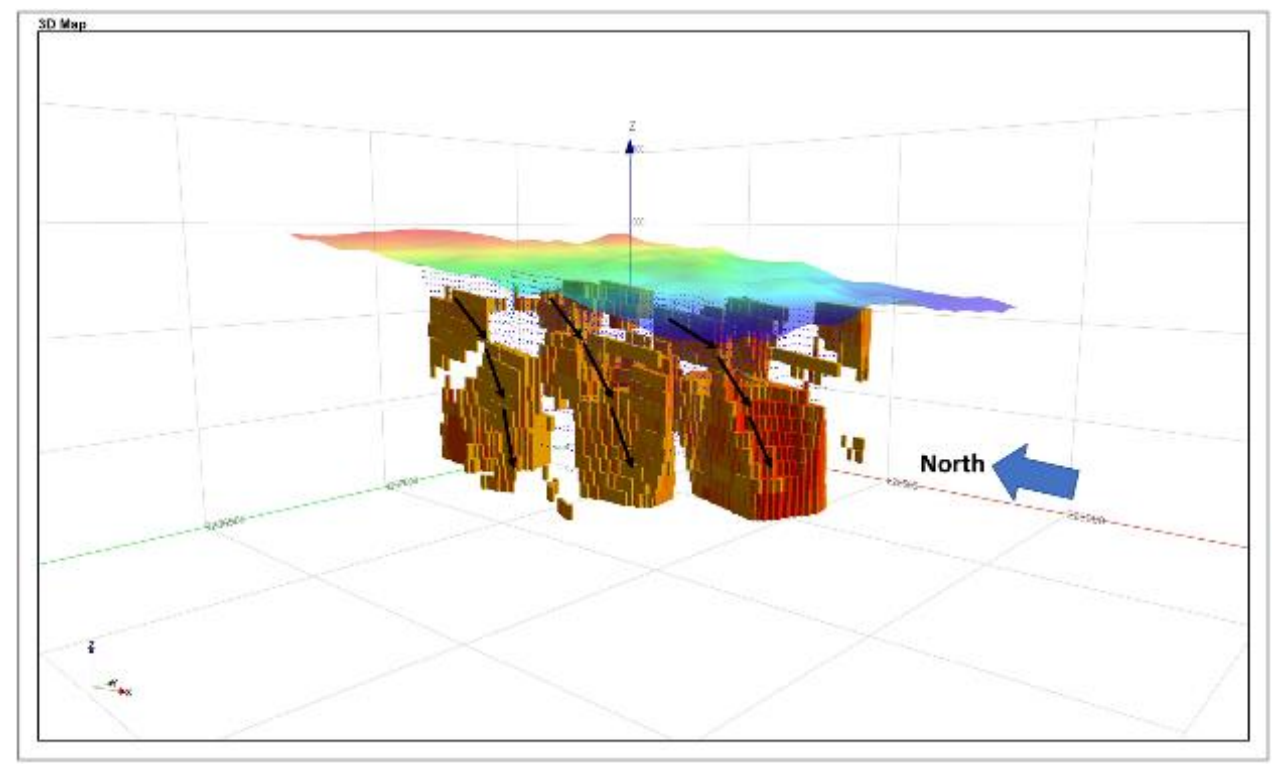

Fig. 13. Side view of 3D model of resistivity interpreted as aquiver.

From the two models presented above, it can be seen that the distribution of the resistivity value interpreted as the axis turns toward the west of the measurement area. Seen in Fig. 12 which shows the distribution of values> 150 Ohm.m originally trending north-south then turn towards southwest. And the lateral distribution can be seen in Fig. 13 where the deflection is not only on the surface but also on the bottom surface. At the bottom of the surface, the distribution of values is found deeper in the southern part compared to the north that turns westward.

\section{Conclusions}

The results of geoelectric survey in Bandorasawetan Village, Cilimus District, Kuningan District with total four geoelectric measurements can be concluded:

1. Based on the resistance value, the existing rock has a resistance value ranging from 5 to $>908$ $\cdot m$, with varying thickness, the grouping based on the resistivity value as follows:

\begin{tabular}{cc}
\hline $\boldsymbol{\rho}(\boldsymbol{\Omega} \cdot \mathrm{m})$ & Description \\
\hline $5-150$ & Low resistivity \\
$>150$ & High resistivity \\
\hline
\end{tabular}

2. Based on regional geological data, the measurement areas enter the depths of the Qyu (The Unadulterated Young Volcano) which has several lithologies: Breksi, Lava, Tufan Sand, and Lapilli from the eruption of Mount Ceremai

3. From the resistivity value that is divided based on the result of correlation with geology concluded that in the measurement area there are 2 types of rock packets. Low resistivity is interpreted as a tufan sand layer that is aquiqlud because it has a smooth material so that the porosity of the rock is smaller

4. The second type of rock package that is high resistivity value that has a more coherent nature and is interpreted as an aquifer breccia in the area of measurement

5. The distribution of the two values varies across each Line, both packets being found starting from the surface to the maximum depth of the geoelectric data modelling.

6. From the fence diagram it can be concluded that the thickness of the high resistivity value that is as the aquifer has dimension which progressively smaller towards East and deeper to the East.

\section{References}

Fetter, 1988, Applied Geology, Merrill Pubs.co. Columbus Ohio United States of America.

Heiken, G. \& Wohletz, K. 1992. Volcanology and Geothermal Energy. University of California Press. Berkeley, Los Angeles, Oxford.

Loke, M.H., 2000, Electrical imaging surveys for environmental and engineering studies; A practical guide to 2-D and 3-D surveys, www.geoelectrical.com.

Loke, M.H., 2004, COURSENOTES: 2-D and 3-D electrical imaging surveys, www.geoelectrical.com.

Reynold, J.M., 1998, An Introduction to applied and environmental geophysics, John Wiley and Sons Inc, New York, p.415.

Santoso, Djoko., 2002., Pengantar Teknik Geofisika., Departemen Teknik Geofisika., Fakultas IImu dan Teknologi Mineral., Institut Teknologi Bandung.

Telford, W.M., Geldart, L.P., Sheriff R.E, 1990, Applied Geophysics, 2nd Edition, Cambridge University Press, p.522. 